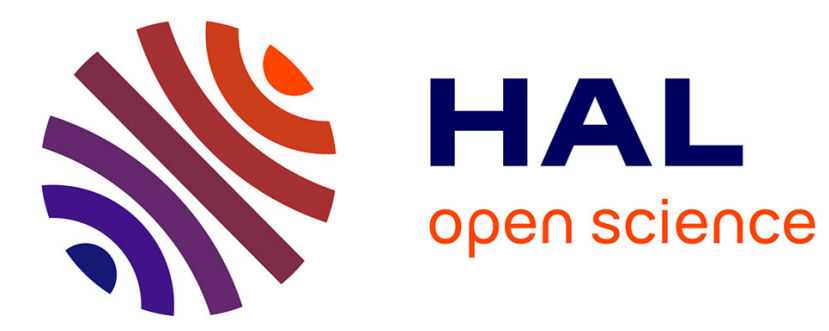

\title{
Numerical study of the Coanda effect in a rotary spray paint atomiser
}

P. Olivas, Philippe Marty

\section{To cite this version:}

P. Olivas, Philippe Marty. Numerical study of the Coanda effect in a rotary spray paint atomiser. Atomisation and Sprays, 2002, 12, pp.769-784. 10.1615/AtomizSpr.v12.i56.140 . hal-00265322

\section{HAL Id: hal-00265322 \\ https://hal.science/hal-00265322}

Submitted on 7 Oct 2020

HAL is a multi-disciplinary open access archive for the deposit and dissemination of scientific research documents, whether they are published or not. The documents may come from teaching and research institutions in France or abroad, or from public or private research centers.
L'archive ouverte pluridisciplinaire HAL, est destinée au dépôt et à la diffusion de documents scientifiques de niveau recherche, publiés ou non, émanant des établissements d'enseignement et de recherche français ou étrangers, des laboratoires publics ou privés. 


\title{
NUMERICAL STUDY OF THE COANDA EFFECT IN A ROTATING SPRAY PAINT ATOMIZER
}

\author{
P. Olivas and $\mathrm{Ph}$. Marty \\ LEGI, Grenoble, France
}

\begin{abstract}
A rotating spray paint atomizer consists of a spinning cup from which paint droplets are ejected. Around the periphery of this disk, an axial air flow blows these liquid particles, which are projected against the surface to be painted. Under some particular circumstances which occur in industry, this axial air flow may be stopped and, owing to the Coanda effect, the radial flow of paint may be attracted backwards in the direction of the atomizer itself. This "reverse flow effect" is detrimental to industrial performance, and it is the purpose of this work to consider the possibility of predicting and even preventing this phenomenon. Using computational software, a simplified model of an atomizer is first considered and the illustration of the reverse flow effect is shown. In the second part, a full numerical modeling of a real geometry is treated and a solution is suggested to improve the performances of this type of equipment. Recommendations are given for an optimal design which prevents the reverse flow effect in a rotating atomizer. For a given air flow rate, it is shown that the bighest output momentum of the jet flow should be obtained.
\end{abstract}

\section{INTRODUCTION}

Electrostatic spray technique is the most common method available for applying liquid paints to metal products such as automotive components. This spray method is based on the principle that negatively charged objects (liquid droplets) are attracted toward positively charged elements, such as car components. Atomized paint droplets are charged at the tip of a spray gun by a charged electrode. Paint can be atomized using conventional air, airless, or rotary systems. The part to be painted, which is attached to a grounded conveyor, is electrically neutral, and the charged paint droplets are attracted toward that part. Most appliance manufacturers use electrostatic sprays [1]. Rotary atomization is a variation of electrostatic spraying that uses centrifugal force generated by a rotating disk with various profiles to atomize the paint which is driven away from the nozzle. The quality of the atomization obtained with this method is excellent.

The present study is based on the technology in use at Sames Corp. (see Fig. 1 and Table 1). The main part of the system is the rotating disk. The central part of the disk is flat, whereas its outer rim is raised. Paint is injected in its center. Its diameter is about $60 \mathrm{~mm}$. This disk is located at the end of a rotating shaft. It is held centrally in its housing by an annular air flow which will be referred to as the "shaft flow." This air flow, of about 60 liters/min, comes through the shaft and is used to keep a gas clearance between the disk and the rest of the structure so that high rotation speed can be reached without contact. The shaft flow, whose mass flow rate is imposed by industrial mechanical constraints, is evacuated through the annular gap between the disk and the external "skirt." Consequently, its speed will depend on the size of the air gap. Although the axial velocity of the shaft flow is limited to a few meters per second, its rotation speed, owing to viscous entrainment by the rotating disk, is between 


\section{NOMENCLATURE}

$d_{1} \quad$ diameter of the skirt flow injection port (m)

$d_{2} \quad$ radial shift between skirt port diameter and rotating disk diameter $\left(=d_{1} / 2-R\right)$ (see Fig. 12$), \mathrm{m}$

$e \quad$ air-gap thickness of the shaft flow, $m$

$b$ distance parameter in the simplified geometry $(\mathrm{m})$

$p \quad$ fluid pressure, $\mathrm{Pa}$

$p_{0} \quad$ atmospheric pressure, $\mathrm{Pa}$

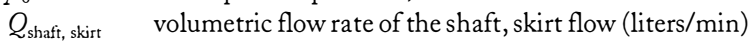

$r, \theta, z \quad$ radial, azimuthal and axial coordinates, $\mathrm{m}$

$R \quad$ rotating disk radius, $\mathrm{m}$

$\mathrm{Re}_{\theta} \quad$ Reynolds number of the spinning disk (= $\left.\Omega R^{2} / \mathrm{v}\right)$

$v_{r}, v_{\theta}, v_{z} \quad$ velocity components, $\mathrm{m} / \mathrm{s}$

$v \quad$ kinematic viscosity, $\mathrm{m}^{2} / \mathrm{s}$

$\rho \quad$ fluid density, $\mathrm{kg} / \mathrm{m}^{3}$

$\Omega \quad$ angular velocity, $\mathrm{rad} / \mathrm{s}$ or $\mathrm{rpm}$

30,000 and 45,000 rpm, giving azimuthal velocities of the order of $120 \mathrm{~m} / \mathrm{s}$. The typical length which can be used to build a Reynolds number, can be the air gap thickness, $e$, or the disk radius, $R$. The first scale gives $\operatorname{Re}_{\text {shaft }}=0.8 \times 10^{4}$ and the second yields $\operatorname{Re}_{\text {shaft }}=2 \times 10^{5}$. The shaft flow is then considered as turbulent.

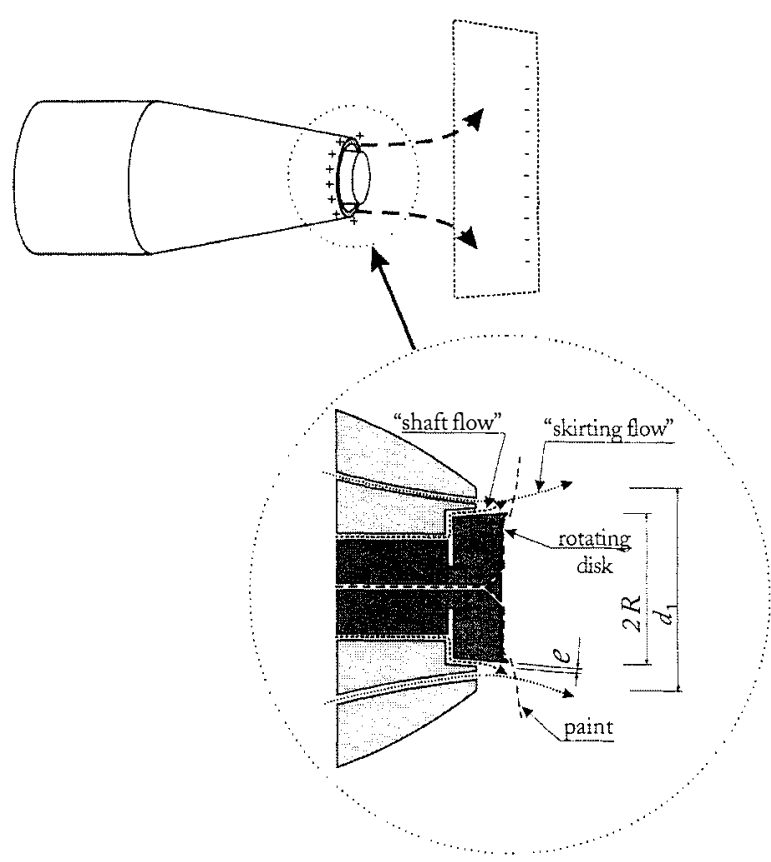

Fig. 1 Rotary paint atomizer: the liquid paint is injected at the center of a rotating disk, which drives it at its rim, where two different air flows assist its atomization into fine droplets. 
Table 1 Main Characteristics of the Atomizer

\begin{tabular}{llll}
\hline Shaft flow & $Q_{\text {shaft }} \approx 60$ liters $/ \mathrm{min}$ & $\begin{array}{l}\text { Annular air gap: } e \approx 1 \mathrm{~mm} \\
\text { Radius } R \approx 30 \mathrm{~mm}\end{array}$ & Axial velocity $\approx 5 \mathrm{~m} / \mathrm{s}$ \\
Skirt flow & $Q_{\text {skirt }} \approx 150$ liters $/ \mathrm{min}$ & $\begin{array}{l}72 \text { holes with diam. } 0.6 \mathrm{~mm} \\
\text { on circle } d_{1} \approx 32 \mathrm{~mm}\end{array}$ & Axial velocity $\approx 150 \mathrm{~m} / \mathrm{s}$ \\
Rotating disk $\quad \Omega \approx 30,000-45,000 \mathrm{rpm}$ & $\begin{array}{l}\text { Disk radius }=R \approx 30 \mathrm{~mm} \\
\text { Azimuthal velocity at }\end{array}$ & $\begin{array}{l}\text { Azim } \\
\text { the rim } \approx 120 \mathrm{~m} / \mathrm{s}\end{array}$ \\
\hline
\end{tabular}

The whole structure is covered with a cylindrical sleeve whose diameter is about $150 \mathrm{~mm}$. The end of the sleeve, which partially covers the circumference of the disk, is the "skirt." The front face of the skirt is drilled with 72 holes around its entire circumference. A strong air jet with flow rate around 150 liters/min issues from these holes. The purpose of this "skirting flow" is to concentrate the cloud of atomized paint and throw it toward the target to be painted.

Owing to unwanted industrial reasons, the "skirting flow" is sometimes suddenly stopped and the atomized cloud of paint may be attracted in the backward direction by the body of the atomizer itself (Fig. 2b) instead of producing a purely radial atomized jet (Fig. 2a).This phenomenon, which will be referred to as "reverse flow effect," gives rise to an important problem as the paint comes to cover the atomizer itself, which then needs to be cleaned with solvent. Such flow behavior is usually referred to as the Coanda effect. This

(a)

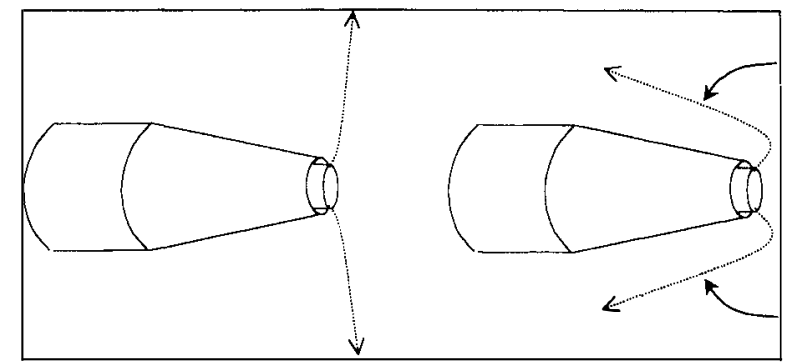

(b)

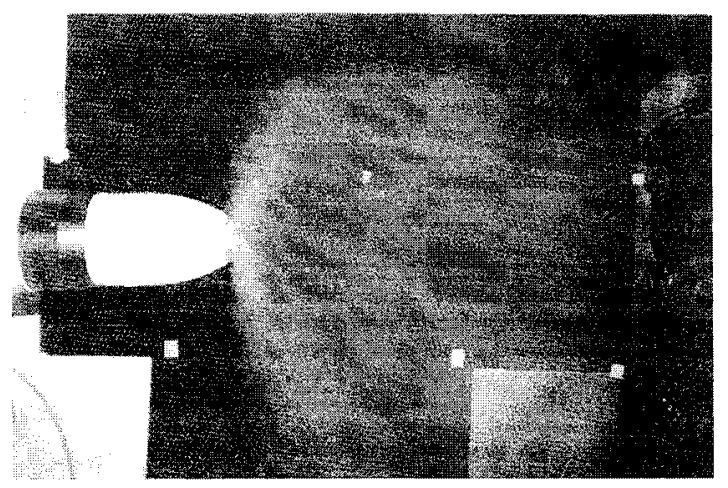

(c)

Fig. 2 (a) Sketch of the normal behavior of the atomizer when the "skirting flow" is stopped. (b) Undesirable "reverse flow phenomenon." (c) Photo of the real atomizer under consideration. 
effect is well known [2] and has also been regularly studied for the positive action it may have on propulsion jets $[3,4]$. It has been presented by Coanda himself as the tendency of a fluid stream which emerges from a nozzle to follow a nearby curved or flat surface, provided that the curvature of the surface or the angle the surface makes with the stream is not too sharp.

The aim of this work is to understand the reasons for this phenomenon and to find solutions to avoid it in order to save time and minimize the use of solvent in the industry. This will be done by using the commercial fluid mechanics computational software Fluent (version UNS 4.1) [5]. Its principle is based on a finite-volume discretization of the transport equations and the continuity equation for an incompressible fluid. Turbulence is modeled using the RNG $k-\varepsilon$ model, which is known for giving good predictions for flows involving swirl. This model has been also recently used with success by Yang et al. [6] for the study of the characteristics of a spray in the chamber of an engine. It is based on the well-established formulation initially proposed by Yakhot and Orszag in 1986 [7]. The flow is assumed to be steady and axisymmetric. Nevertheless, each of the three velocity components has to be determined, justifying the label2D1/2 which is sometimes given to this type of swirling axially symmetric flow. A second-order discretization scheme is used for the modeling of the convection terms. It is noteworthy to mention the existence of a recent similar approach by Domnick et al. [8], who have used the same commercial code for the modeling of a high-speed bell atomizer. The numerical results in their work compare fairly with the experiments, and both standard and RNG $k-\varepsilon$ models have been used.

In the next section, two simplified geometries of atomizer will be considered with the aim of testing the ability of the computer code to reproduce the Coanda effect and to obtain more detailed insights into the physics of this phenomenon. In the last section, a real industrial geometry will be considered and an optimized design will be suggested.

\section{MODELING THE REVERSAL EFFECT}

Two simplified geometries have been studied in order to understand the "reverse flow" phenomenon:

1. A single thick rotating disk with a radius $R$ which is located at distance $b$ from a stationary wall (see Fig. 3)

2. The same rotating disk with a fixed solid body attached to its back and a wall facing its front side (see Fig. 4)

Concerning the first geometry, the radius $R$ is equal to $30 \mathrm{~mm}$, similar to its value in an industrial rotating spray atomizer. The fluid is air with a kinematic viscosity $v=$ $1.5 \times 10^{-5} \mathrm{~m}^{2} / \mathrm{s}$ and density $\rho=1.22 \mathrm{~kg} / \mathrm{m}^{3}$. The angular velocity has been varied in the range $3000 \mathrm{rpm} \leq \Omega \leq 45,000 \mathrm{rpm}$ (thus $2 \times 10^{4} \leq \operatorname{Re}_{\Omega}=\Omega R^{2} / v \leq 3 \times 10^{5}$ ) in order to see its influence on the Coanda phenomenon. Constant pressure conditions have been imposed at the external boundaries, which are located at $7 R$ from the $z$ axis in the radial direction and at $4-6 R$ from the disk surface in the axial direction. The distance ratio $b / R$ has been given values varying from 1 to 3 .

Preliminary computations have been done for $\operatorname{Re}_{\Omega}=\Omega R^{2} / v=1.8 \times 10^{5}$ and $\mathrm{h} / R=$ 1 with three different cell arrangements and external boundaries positions: 


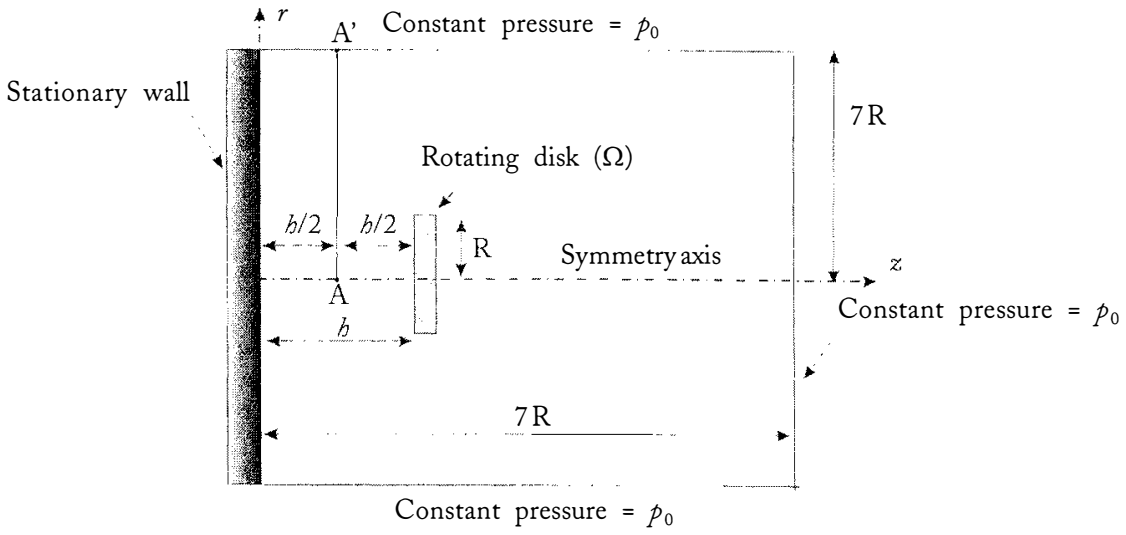

Fig. 3 First simplified geometry: single rotating disk with a stationary wall close to it.

- The first mesh consists of 1200 regularly spaced rectangular cells with external boundaries at distances indicated in Fig. 4.

- The second mesh keeps the same position of the boundaries but the number of rectangular cells has been multiplied by a factor of 4 (4800 constant size cells).

- In the third mesh, the external boundaries have been moved to a distance equal to twice that of the two preceding cases and a refinement has been done near the disk. The number of cells is equal to 2400 (see Fig. 5a).

Figure $5 \mathrm{~b}$ shows the radial profile of the azimuthal velocity $v_{\theta}$ along the line $A A$ 'shown in Fig. 3 and located at mid-distance between the wall and the rotating disk. The order of magnitude of $v_{\theta}$ (as well as the streamlines pattern, which is not shown) remains almost unchanged, and this allows us to conclude that the sensitivity to the grid was rather limited and that the radial position of the lateral constant-pressure boundary is not a crucial issue as far as it is reasonably distant from the symmetry axis.

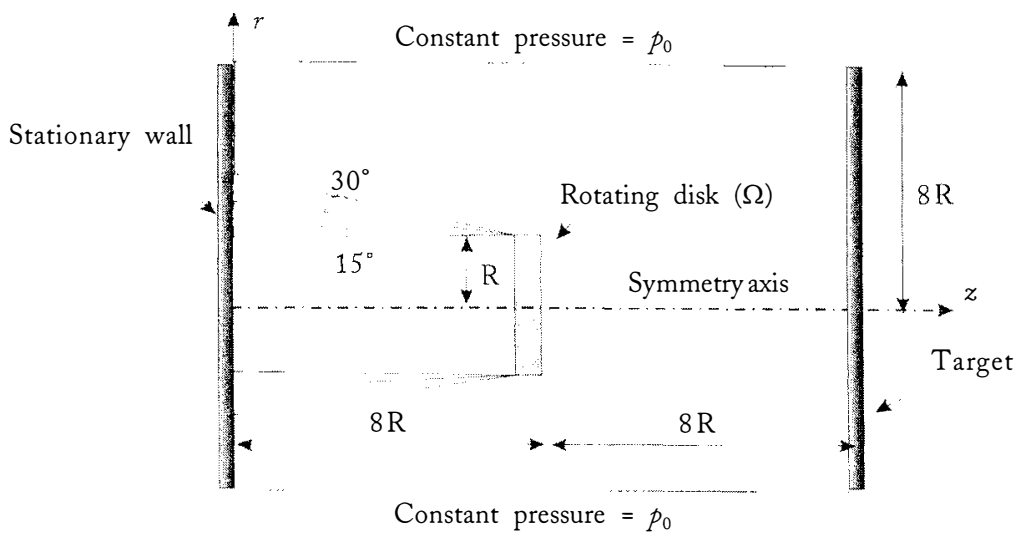

Fig. 4 Second simplified geometry: rotating disk attached to a fixed solid body at its rear. 

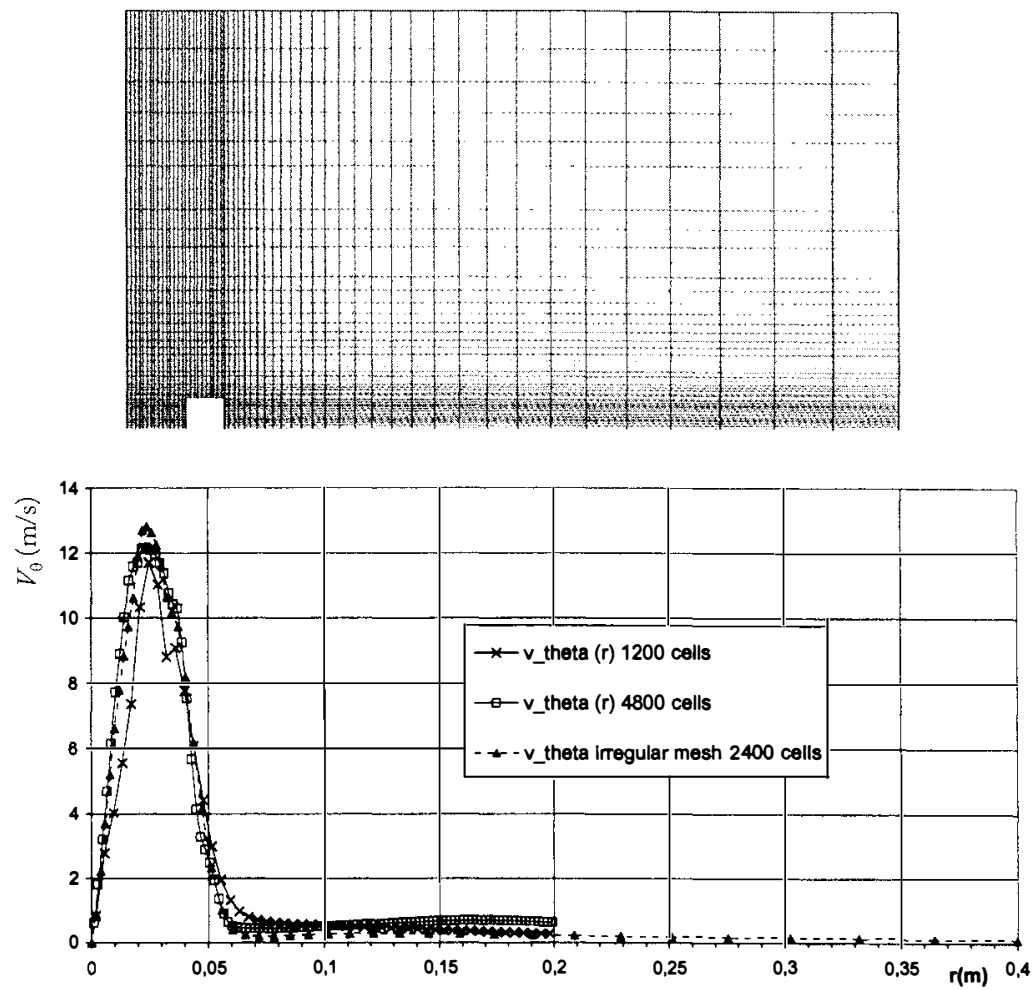

Fig. 5 (a) Irregular mesh used in the third test. (b) Radialprofiles of the azimuthalvelocity along the line $A A^{\prime}$ 'shown in Fig. 3 for three different meshes $\left(b / R=1 ; \operatorname{Re}_{\Omega}=\Omega R^{2} / v=1.8 \times 10^{5}\right)$.

The results of this first simplified case showed the importance of the distance ratio $h / R$. When looking at the radial distribution of the swirl velocity in the internal gap between the wall and the rotating disk (line $A A^{\prime}$ ) one can see (Fig. 6) that, when $h / R$ becomes smaller than 1.5 , the air in this region is suddenly driven into rotation so that the maximum value of $v_{\theta}$ jumps from 1 to $12 \mathrm{~m} / \mathrm{s}$.

As could be expected, the rotation of the disk produces a radial ejection of the fluid and, due to mass conservation, an axial flow directed toward the disk. The phenomenon is illustrated in Fig. 7. Choosing $h / R=3$ (Fig. 7a) shows that the radial ejection remains strictly symmetrical with respect to the two faces of the disk. When $b / R$ becomes smaller, the meridional flow between the wall and the rotating disk almost disappears and is replaced by a static equilibrium in which centrifugal forces are simply balanced by a radial pressure gradient. This results in a flow with a small recirculation zone and a clearattraction of the radial jet toward the wall. This is shown in Fig. 7b, where $b / R=1$. Figure 8 shows the modification of the pressure profile along $A A$, illustrating the influence of the wall on pressure conditions. One can see that, in the case where the wall is close enough to the $\operatorname{disk}(b / R<1.5)$, a strong depression appears between the wall and the rotating disk. As the conditions of pressure at infinity are being imposed $\left(p_{0}\right)$, this depression naturally attracts the mean flow toward the wall. This deviation of the flow illustrates the "wall effect," which, in the case of the atomizers 


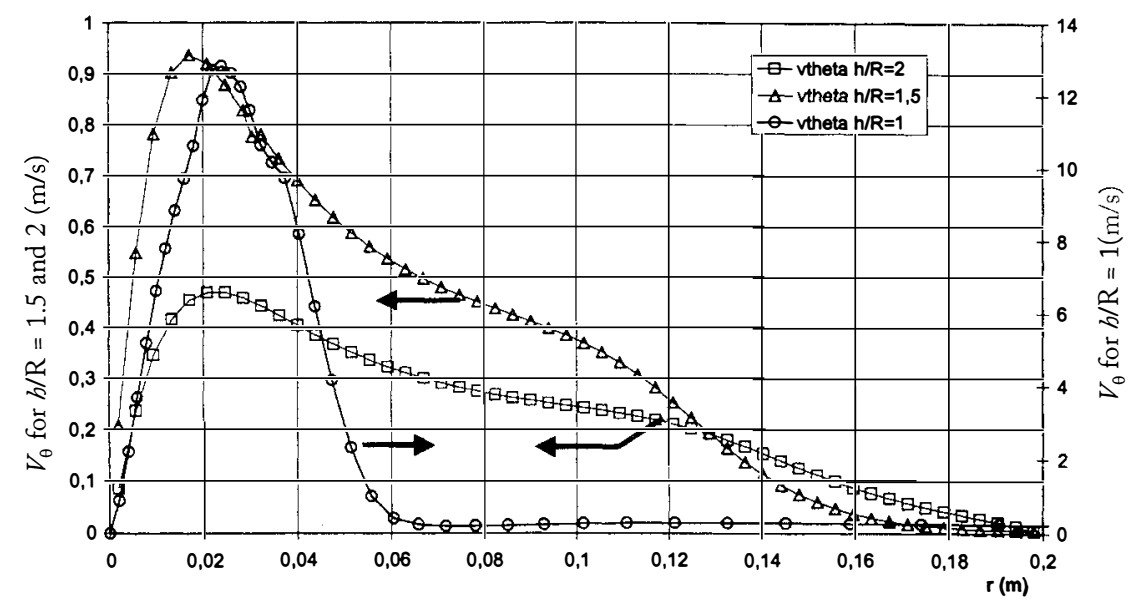

Fig. 6 Distribution of swirl velocity in the internal gap between the stationary wall and the rotating disk (line $A A^{\prime}$ in Fig. 3) for various values of $h / R$ and $\mathrm{Re}_{\Omega}=2 \times 10^{5}$.

studied here, gives rise to the unwanted and undesirable phenomenon of "reverse flow" effect mentioned earlier.

In order to get closer to the real configuration shown in Fig. 1, a second simplified geometry with a fixed solid conical body attached to the rotating disk (see Fig. 4) has been considered to evaluate the effect of the slope of the edge of the rear body. In addition, a solid wall representing the part to be painted has been placed in front of the right side of the disk. As shown in Fig. 9, it was found that when the edge of the body has a slope of around $30^{\circ}$ (or more), the behavior of the flow is completely modified. Whatever the disk speed, a depression zone builds up along the body. The air surrounding this part is driven into rotation and the mean flow is attracted by the body, similar to what was observed in the first simplified geometry.

In the case where the flow is reversed, one can see (Fig. 10a) that a depression zone grows up near the rim of the disk and along the static body, keeping the angular momentum confined in its vicinity (Fig. 10b).

The first part of this study gives rise to several conclusions:
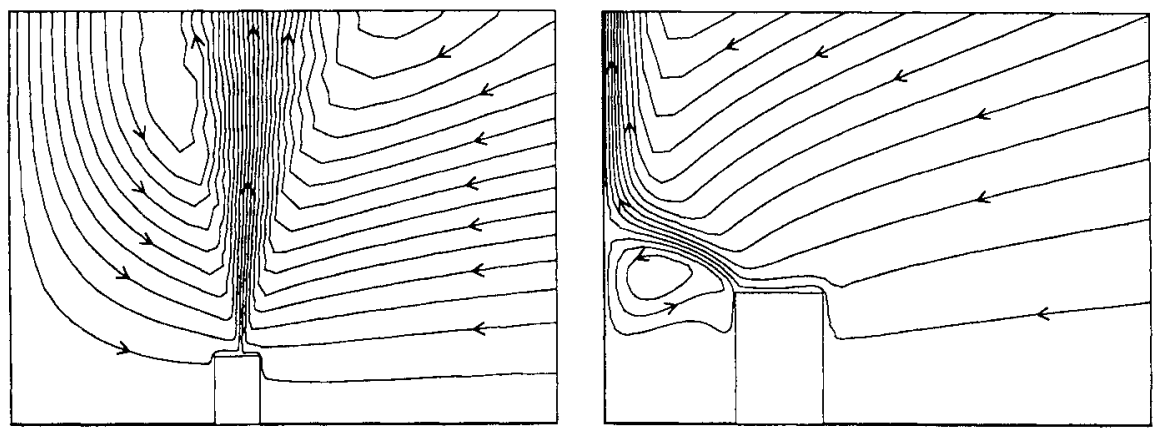

Fig. 7 Streamlines pattern for $\operatorname{Re}_{\Omega}=1.8 \times 10^{5}$ and (a) $b / R=3$, (b) $b / R=1$. 


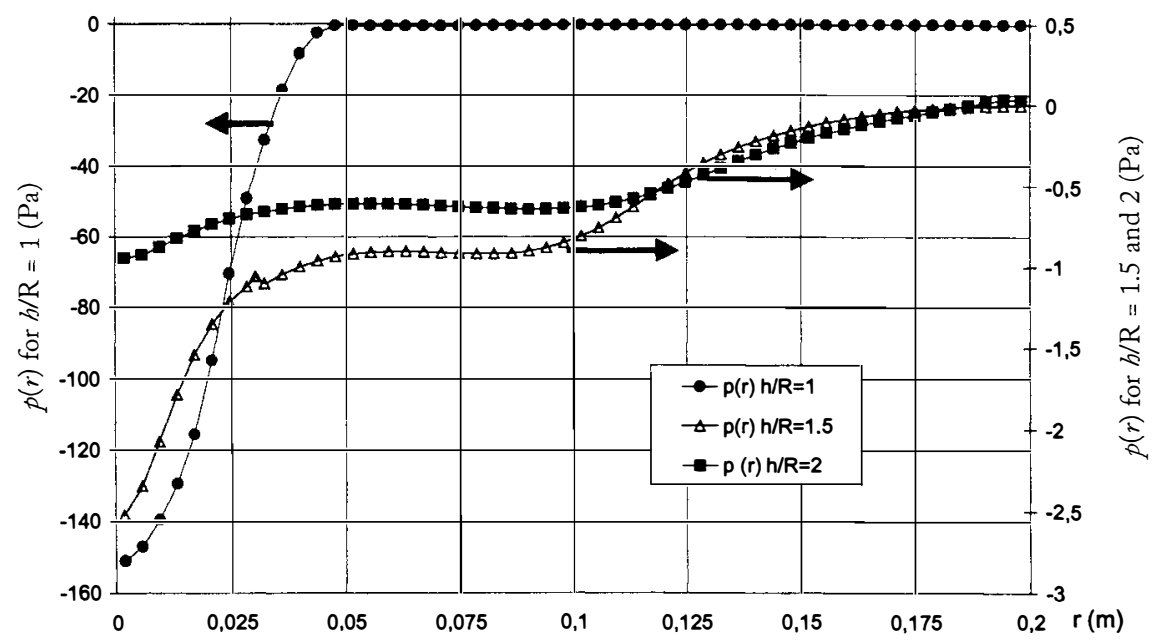

Fig. 8 Distribution of pressure along the line $A A^{\prime}$ for various values of $h / R$ and $\operatorname{Re}_{\Omega}=1.8 \times 10^{5}$.

1. Although the results presented in this section concentrate on a particular value of the Reynolds number, the rotation velocity of the cylinder has been shown to have a negligible influence on the characteristics of flow. As a matter of fact, it has been shown that the streamlines pattern and the entire flow field was almost not influenced by the value of $\mathrm{Re}_{\Omega}$, at least in the range which has been investigated (from $2 \times 10^{4}$ to $3 \times 10^{5}$ ). This could be expected by considering that both pressure and inertia forces are proportional to the square of the rotation speed $\Omega^{2}$ and that these two terms will balance each other.

2. For the case of a rotating disk which induces movement of the surrounding air, there exists a critical ratio between the distance $b$ of a side stationary obstacle and the radius, $R$, of the disk, which involves the attraction of the meridional jet generated toward this obstacle. This critical ratio is about $b / R=1$.

3. When this obstacle is attached to the rotating cylinder, the angle of incidence which its surface presents with the prolongation of the cylinder also has a critical value of around $30^{\circ}$.

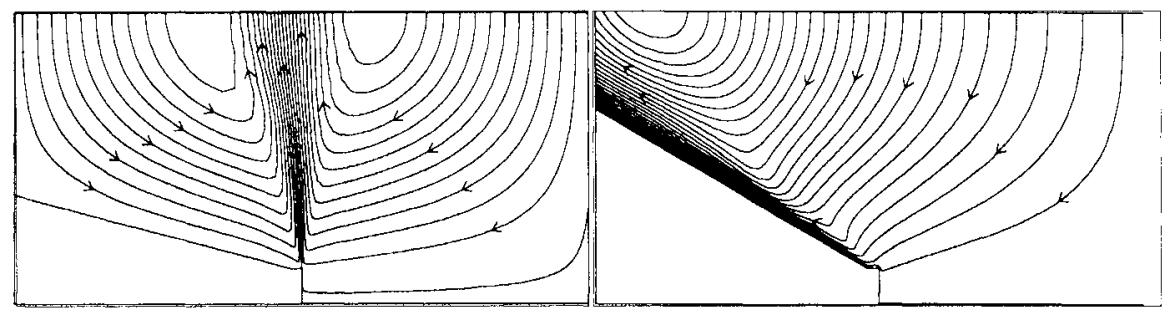

Fig. 9 Streamlines distribution for $\operatorname{Re}_{\Omega}=1.8 \times 10^{5}$ and two different angles of the rear body shown in Fig. 4: (a) $15^{\circ}$; (b) $30^{\circ}$. 

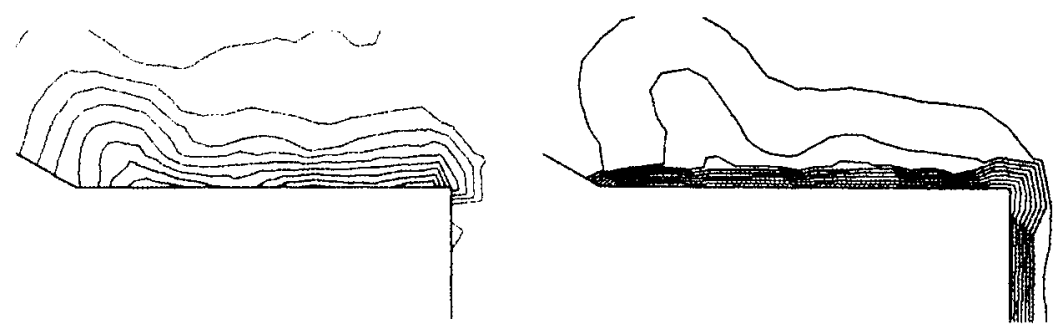

Fig. 10 A reverse flow has occurred for an angle equal to $30^{\circ}$ : (a) pressure distribution, 10 isolines ranging from $P=94$ to $0 \mathrm{~Pa}$; (b) swirl velocity distribution, 10 isolines ranging from $V_{\theta}=0$ to $94 \mathrm{~m} / \mathrm{s}$ at the wall $\left(\operatorname{Re}_{\Omega}=2 \times 10^{5}\right)$.

4. The presence of the obstacle at the rear of the disk generates a limitation to the intensity of the recirculating meridional flowbetween the rear wall and the disk. This prevents the evacuation of the angular momentum which is responsible for the appearance of the reverse flow effect. This observation will be the guideline of the next section, which will consider the possibility of improving actual atomizers.

\section{GLOBAL MODELING OF THE FULL SYSTEM UNDER WORKING CONDITIONS}

The above work is not sufficient to explain the behavior of a real industrial configuration. An industrial device has three main differences from the simplified geometries described in the previous section: (1) the geometry is more sophisticated (for example, the rotating piece is not completely flat, but has a rim which is raised); (2) as already discussed, the rotation of the disk needs the use of a shaft flow (see Fig. 1); (3) during the painting sessions a strong skirting flow is used to concentrate the paint. This section will be composed of three parts:

- The first part will model an already existing atomizer (as shown in Fig. 2c) whose disk has a constant diameter. As it is the aim of this work to study the reverse flow effect when no skirt flow exists, this flow will be maintained to zero in this part $\left(Q_{\text {skirt }}=0\right)$.

- In light of the preliminary tests which have been described in the previous section, it seems interesting to take advantage of the shaft flow to facilitate the radial ejection of the fluid particles having a high rotation rate in order to avoid the reverse effect. This has led to a geometric modification which is described in the second part. Here also, the skirt flow will be equal to zero.

- Finally, the third part will present a modeling of the enhanced geometry in which the skirt flow is added. The influence of the initial angle of the skirt flow will be studied (i.e., different angles of the jets with respect to the horizontal direction will be tested).

In this section, the rotation speed of the disk has been kept to $45,000 \mathrm{rpm}$ so that $\operatorname{Re}_{\Omega}$ $=2.8 \times 10^{5}$. 


\section{Modeling an Existing Atomizer}

An unstructured mesh of about 8000 triangular cells was employed (see Fig. 11). The rotating disk has a cylindrical shape (the external surface has a constant diameter). This type of disk is the most commonly used type in industrial applications.

This first part has allowed the validation of the numerical method, as the calculation results showed excellent agreement with the experimental tests carried out on site. The reverse flow effect, in particular, has been observed to occur in the numerics for the same values of the parameters as in the experiments. As written before, special attention was given to the shaft flow. This flow is evacuated in the periphery of the disk, and one question was to understand the influence of its parameters (angle or flow rate, for example) on the behavior of the global flow and especially on the reverse flow effect. Two cases were modeled:

1. In the first case, the geometry shown in Fig. 11 was kept unchanged (the air-gap is constant and equal to $1.5 \mathrm{~mm}$ ) but the speed of the shaft flow was increased gradually ${ }^{1}$ from $4 \mathrm{~m} / \mathrm{s}$ up to $16 \mathrm{~m} / \mathrm{s}$ (this yields an increase of the air flow rate). The results are presented in Table 2 , where the average direction of ejection is indicated.

2. In the second test (Table 3), the same geometry was used but the air-gap size was changed $(e=1.5,1.0$, and $0.5 \mathrm{~mm})$. The value of the flow rate was kept constant and equal to $Q_{\text {shaft }}=65$ liters $/ \mathrm{min}$ and, consequently, the air gap thinning increases the speed of the gas outlet by a factor of 3 .

These simulations corroborate the importance given to the evacuation of angular momentum confined between the rotating piece and its surrounding "skirt." It appears that an axial speed of about $10 \mathrm{~m} / \mathrm{s}$ or more in the air gap can avoid the reverse flow effect.

These conclusions made it possible to improve the actual systems of pulverization by paying more attention to the shape and dimensions of the air-gap.

${ }^{1}$ The typical air gap thickness is $1.5 \mathrm{~mm}$ and its radius is $\sim 30 \mathrm{~mm}$ : as the flow rate of the shaft flow is about 65 liters $/ \mathrm{min}$, the nominal velocity is $\sim 4 \mathrm{~m} / \mathrm{s}$.
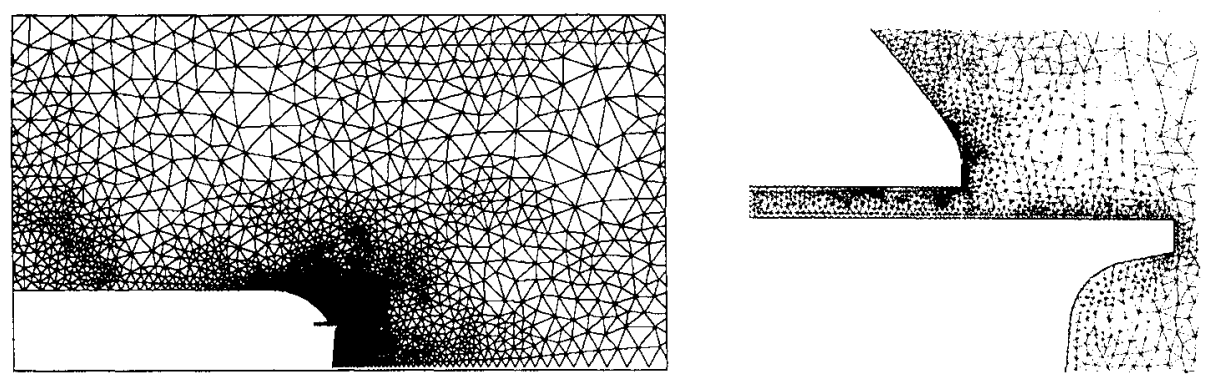

Fig. 11 Axisymmetric meshing of the real geometry (the atmospheric pressure is imposed on the left and upper boundaries; a wall standing as the target is imposed on the right boundary). 
Table 2 Flow Behavior for $\operatorname{Re}_{\Omega}=2.8 \times 10^{5}$ and $Q_{\text {skirt }}=0$ with a Fixed Air Gap Thickness $(e=1.5 \mathrm{~mm})$ and Various Shaft Flow Rates

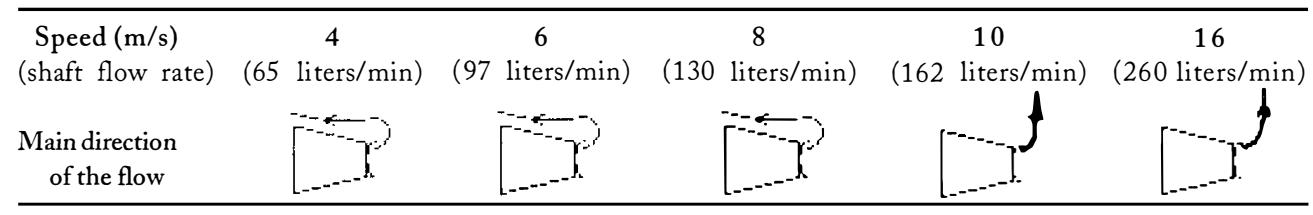

\section{Improved Design of the Rotating Disk}

We present here a new geometry of rotating disk that could increase the performance of the system. A rotating disk with a conical external surface (with an external diameter that varies) has been tested. It has given better results concerning the occurrence of the reverse flow effect, supporting the idea that the effect of "radial evacuator" provided by the diverging shape of the disk can contribute to the evacuation of the angular momentum in a direction approaching that of the main flow. This geometry was modeled for a series of simulations.

Several new meshes of about 8000 triangular cells (see Fig. 12a) were used for this new geometry, depending on the parameters $d_{2}$ and $e$ that are shown in Fig. 12b. The disk rotation speed is still 45,000 rpm.

The behavior of this new geometry regarding the reversal effect is tested with variation of two geometric parameters corresponding to the size of the surrounding fixed body $\left(d_{2}\right)$ and the size of the air gap $(e)$.

The results are presented in Table 4 and show a global improvement of the performance of the system. The " $\mathrm{X}$ " indicates that the configuration $\left(d_{2}\right.$ versus $\left.e\right)$ is unstable as both behaviors could be found, depending on initial conditions. ${ }^{2}$

Concerning the size of the atomizer itself, it was found that an increase of approximately $10 \%$ of the external diameter of the "skirt" generates the appearance of a reversal.

Concerning the effect of the air gap size, $e$ : as for the disk geometry, one finds that for a constant flow rate, the thinning of the air gap prevents the reversal. However, this new geometry makes it possible to use "air gaps" at least $20 \%$ larger than in the existing geometry.

${ }^{2} \mathrm{An}$ initialization of the flow field with a velocity equal to zero will make the solution converge toward a "reversed flow," whereas an initialization with a velocity field which is not reversed will converge to a solution which is also not reversed.

Table 3 Flow Behavior for $\operatorname{Re}_{\Omega}=2.8 \times 10^{5}$ with a Fixed Flow Rate $\left(Q_{\text {shaft }}=65\right.$ liters $/ \mathrm{min}$ ) and Different Air Gap Thicknesses

\begin{tabular}{lccc}
\hline $\begin{array}{l}\text { Air gap (mm) } \\
\text { (speed) }\end{array}$ & $\begin{array}{c}1.5 \\
\mathrm{~m} / \mathrm{s})\end{array}$ & $\begin{array}{c}1.0 \\
(6 \mathrm{~m} / \mathrm{s})\end{array}$ & $(12 \mathrm{~m} / \mathrm{s})$ \\
$\begin{array}{l}\text { Main direction } \\
\text { of the flow }\end{array}$ & {[}
\end{tabular}


(a)
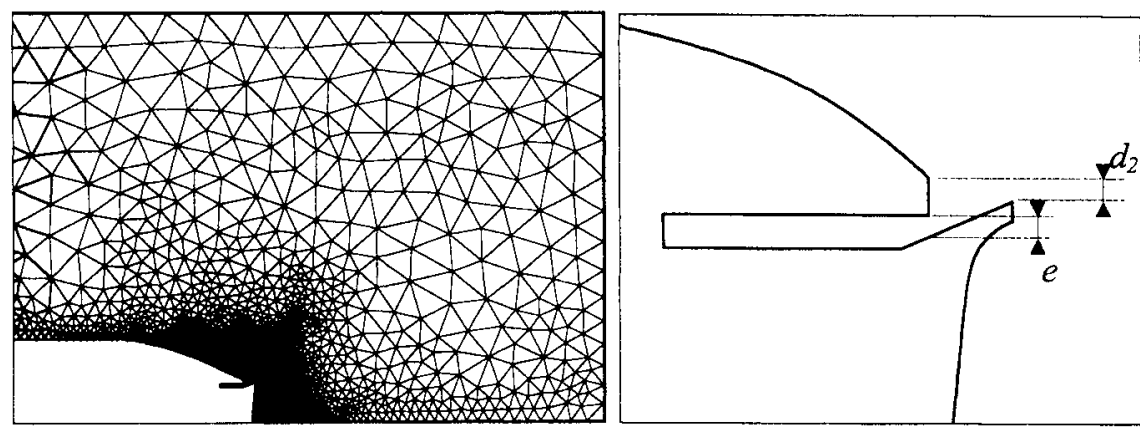

(b)

Fig. 12 (a) Meshing of the enhanced "conical" geometry; (b) close-up view when $d_{2}=2 \mathrm{~mm}$ and $e=1.7 \mathrm{~mm}$.

\section{Atomizing Behavior of the Improved Atomizer}

In this part we test the above-described enhanced conical geometry under full atomization conditions, i.e., with addition of the skirt flow. This flow is actually provided by several discrete holes which are located on a circle at the tip of the skirt. In order to use an axisymmetric model, an annular gap having the same cross section as the 72 holes has been included in the mesh to account for the skirt flow in the computation. A refined triangular mesh with 43,000 cells was used to describe the geometry. A stationary wall is placed at a distance of $25 \mathrm{~cm}$ from the rotating disk. External boundaries with constant pressure are located at $30 \mathrm{~cm}$ from the symmetry $\mathrm{O} z$ axis. Figure 13 shows the streamlines pattern and the velocity contour near the rotating disk. The existence of the recirculating zone already mentioned at the beginning of this article is noticed in Fig. 13a. Figure 14, which shows the radial profile of $v_{z}$ at mid-distance between the disk and the target (i.e., at $12.5 \mathrm{~cm}$ from the disk) confirms this point, which was already mentioned by Domnick et al. [8] (see Fig. 9 in their article). One could ask about the dependence of these results on the quality of the mesh. Actually, in Fig. 14, a $v_{z}$ profile obtained with a coarser grid made of 15,800 cells is shown, and no significant difference is to be seen.

Figure 15 shows the trajectories of water droplets of 20,35 , and $50 \mu \mathrm{m}$ in diameter injected at the rim of the rotating disk. Although a bigger droplet will first experience a wider radial excursion, all the trajectories become the same as these droplets approach the target.

Table 4 Main Jet Behavior When $d_{2}$ and $e$ are Varied with a Constant Air-Shaft Flow Rate and $\Omega=45,000 \mathrm{rpm}$

\begin{tabular}{ccccccc}
\hline $\begin{array}{c}\text { Air gap } e(\mathrm{~mm}) \\
d_{2}(\mathrm{~mm})\end{array}$ & 1.0 & 1.2 & 1.7 & 2.2 & 2.7 & 3.2 \\
-2 & & & & & \\
0 & & & & & \\
1 & & & $\mathrm{X}$ & & & \\
2 & & & & & \\
5 & & & & & \\
\hline
\end{tabular}




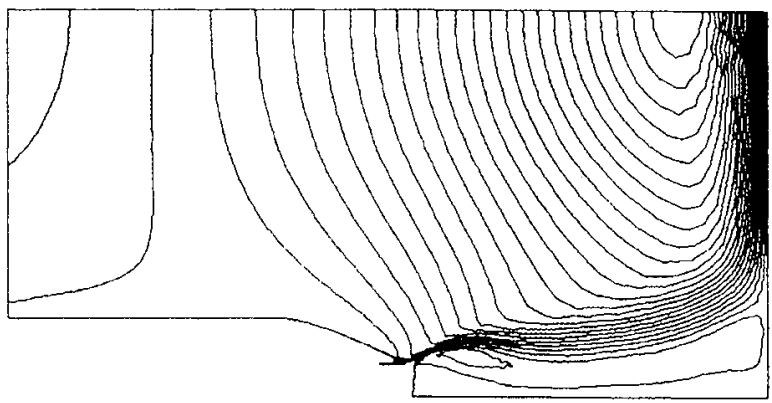

(a)

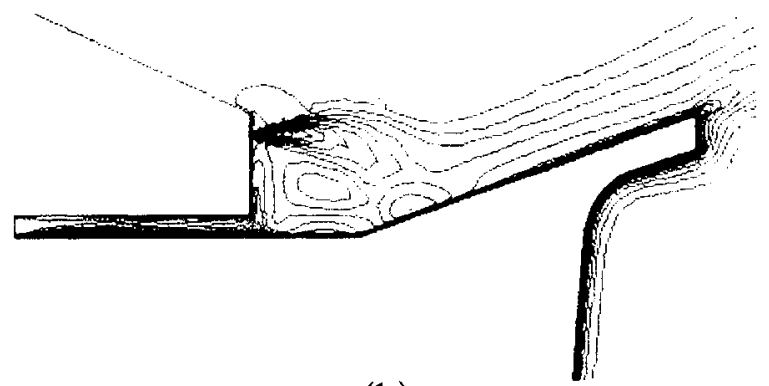

(b)

Fig. 13 Streamlines (a) and velocity contours (b) in the enhanced atomizer with $Q_{\text {shaft }}=65$ liters $/ \mathrm{min}, Q_{\text {skirt }}=160$ liters $/ \mathrm{min}, \Omega=45,000 \mathrm{rpm}$, angle of the skirt jet $=0^{\circ}$.

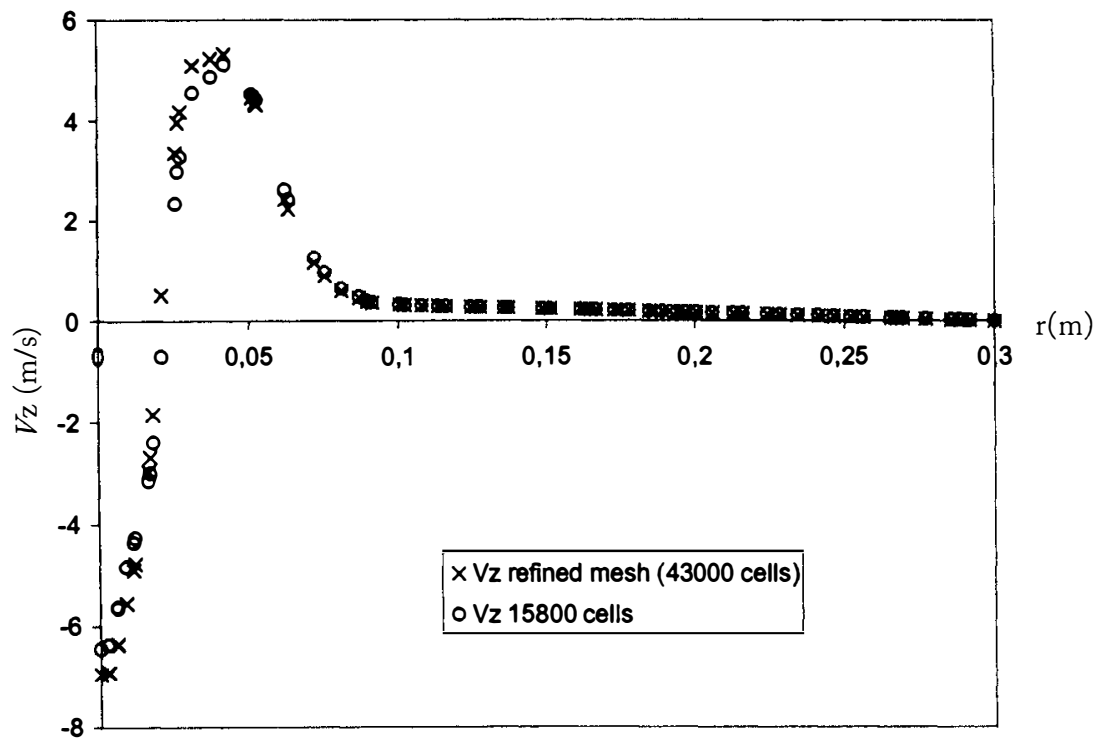

Fig. 14 Influence of the mesh refinement on the radial profiles of the axial velocity $v_{z}$ along a radial line located at mid-distance between the disk and the target (same parameters as in Fig. 13). 
In addition to its assistance in the atomization of the liquid paint, the purpose of the skirt jets is

- To obtain a diameter of the pulverized spray as small as possible in the vicinity of the target, in order to increase the transfer efficiency (i.e., the percentage of paint which will really be deposited on the target)

- To produce an axial speed as weak as possible when approaching the target

These criteria (diameter and speed of the spray) were used to test the influence of the angle of incidence of the "skirting flow" on the system effectiveness, and it was finally shown that this angle has a negligible effect (see Table 5).

It is finally interesting to compare the total air flow rate which is induced by the rotating disk and the turbulent viscous shear created by the skirt jets to the amount of air which is injected by the atomizer itself (i.e., $Q_{\text {shaft }}+Q_{\text {skirt }}=225$ liters $/ \mathrm{min}$ in this case). This total flow rate can be deduced from Fig. 16, which represents the evolution of the radial velocity along the constant-pressure outlet boundary located at $r=30 \mathrm{~cm}$. A rough estimate of the surface integral yields a radial outflow equal to 4500 liters $/ \mathrm{min}$. It is remarkable that this flow rate is approximately 20 times bigger than that injected by the atomizer itself.

\section{CONCLUSION}

The air flow in a rotating spray paint atomizer has been modeled numerically. The variety of calculations carried here validates the ability of modern numerical tools to simulate this

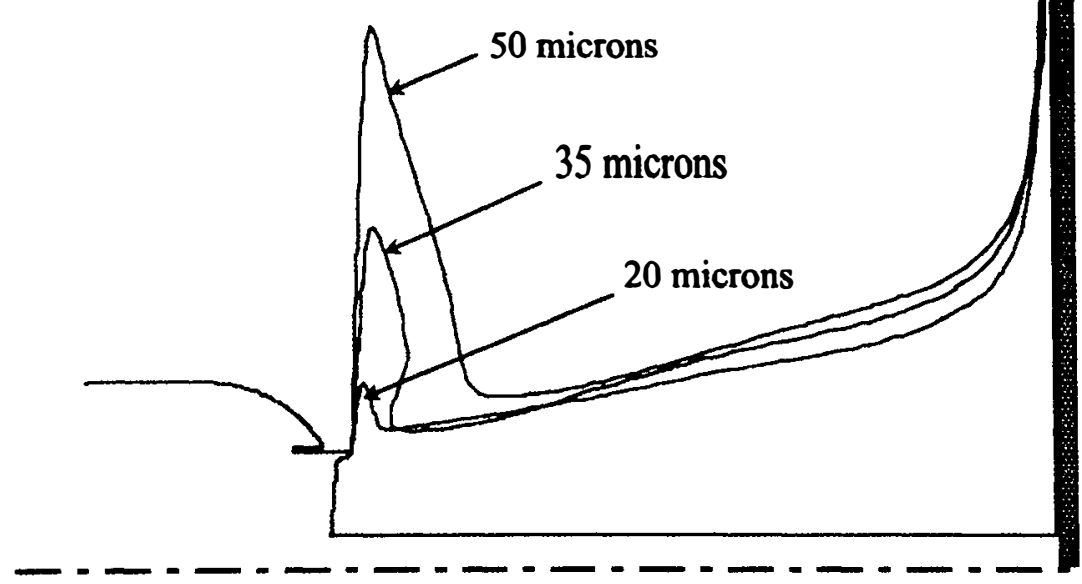

Fig. 15 Particle paths in the enhanced atomizer with $Q_{\text {skirt }}=160$ liters $/ \mathrm{min}, Q_{\text {shaft }}=60$ liters $/ \mathrm{min}$, and $\Omega=45,000 \mathrm{rpm}$ (size of the particles: 20,35 , and $50 \mu \mathrm{m}$ ). 
Table 5 Speed and Diameter of the Spray for D ifferent An gles of In cidence of th e Sk irting Flow

\begin{tabular}{ccccc}
\hline Angle & $0^{\circ}$ & $\begin{array}{c}-16^{\circ} \\
\text { (convergent) }\end{array}$ & $\begin{array}{c}-30^{\circ} \\
\text { (convergent) }\end{array}$ & $\begin{array}{c}+16^{\circ} \\
\text { (divergent) }\end{array}$ \\
\hline Jet dimensions & $V_{z} \max =2.4 \mathrm{~m} / \mathrm{s}$ & $V_{z} \max =2.3 \mathrm{~m} / \mathrm{s}$ & $V_{z} \max =2.3 \mathrm{~m} / \mathrm{s}$ & $V_{x} \max =2.35 \mathrm{~m} / \mathrm{s}$ \\
& $V_{\theta} \max =2.0 \mathrm{~m} / \mathrm{s}$ & $V_{\theta} \max =2.1 \mathrm{~m} / \mathrm{s}$ & $V_{\theta} \max =2.2 \mathrm{~m} / \mathrm{s}$ & $V_{\theta} \max =2.0 \mathrm{~m} / \mathrm{s}$ \\
$r\left(V_{z} \max \right)$ & $=75 \mathrm{~mm}$ & $r\left(V_{z} \max \right)=72 \mathrm{~mm}$ & $r\left(V_{z} \max \right)=72 \mathrm{~mm}$ & $r\left(V_{x} \max \right)=74 \mathrm{~mm}$ \\
\hline
\end{tabular}

type of equipment. Numerical simulations can bring important information, helping to produce recommendations for the development of prototypes. For example, they can help in designing the shaft flow, the air gap, or the shape of the external face.

The occurrence of the reverse flow effect has been explained and illustrated by a simplified geometry. It has been shown that a decrease of the distance between the rotating disk and the rear wall induces a depression in the zone located between the disk and the wall, and that this depression attracts the radial meridional jet ejected by the rotating disk.

The importance of the shaft flow for the occurrence of the reversal has been revealed: it has been shown that this flow takes part in the evacuation of the fluid in rotation, and can prevent the creation of a depression in the vicinity of the rotating body. Other parameters such as the shaft air flow rate and the dimensions of the surrounding body have been shown to be important as well.

The major result of this work is that, for a given shaft flow rate, one should seek a maximum value of the output momentum, i.e., $\rho V^{2} S_{\text {shaft }}$. Unless the pressure drop in the air gap becomes too high, the smallest value of its thickness should be looked for in the design of an atomizer to prevent the occurrence of the reverse effect.

These simulations allow recommending a new geometry for the system, with optimized shape (conical), air gap (smaller), and surrounding body (smaller).

The influence of the "skirting flow" on the meridional flow pumped by the rotating disk has been studied: it shows the weak influence of the incidence angle of this air flow on the dimension of the plume projected on the target to be painted. Also, the diameter of this plume as well as its axial speed have been studied.

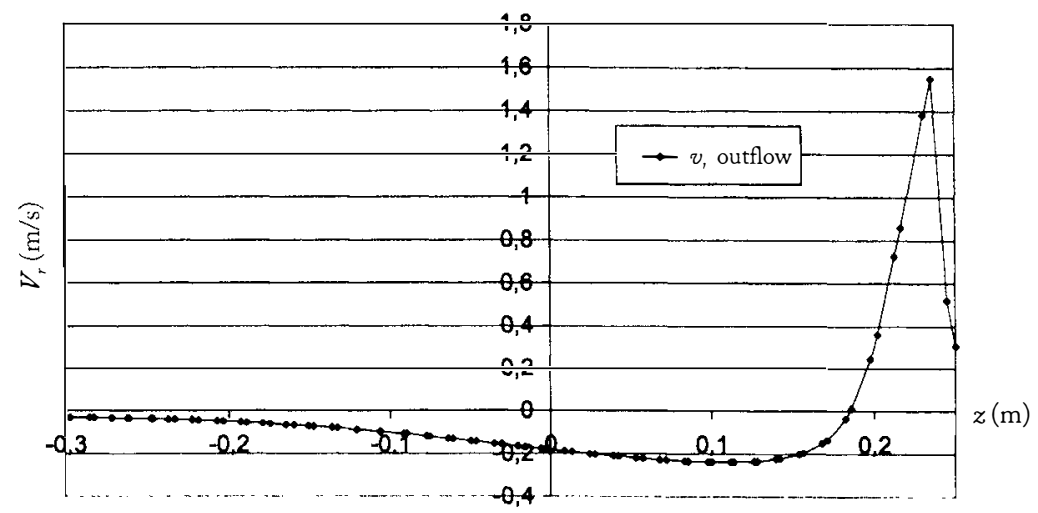

Fig. 16 Axial profile of the radial velocity $v_{r}$ along the constant-pressure outlet boundary (same parameters as in Fig. 13). 


\section{REFERENCES}

1. Binks Manufacturing Company, Compressed Air Spray Gun Principles, TD10-1R-4, Binks Training Division, Franklin Park, IL, 1998.

2. H. Coanda, Procédés et dispositifs pour faire dévier une veine fluide pénétrant dans un autre fluide, brevet $\mathrm{n}^{\circ} 788.140,1934$.

3. M. Kadosch, Mécanisme de la déviation des jets propulsifs, Publications Scientifiques et Techniques du Ministère de l'Air, Paris, France, 1959.

4. C. D. Hope-Gill, An Experimental Investigation into the Shape of Thrust Augmenting Surfaces in Conjunction with Coanda-Deflected Jet Sheets, Part I, ITIAS t.n. 70, Toronto, Canada, 1964.

5. Fluent, Inc., Fluent User's Guide, Fluent Incorporated, Lebanon, NH, 1996.

6. H. C. Yang, H. S. Ryou, K. B. Hong, H. S. Kim, and S. K. Park, Application of the RNG $k-\varepsilon$ Model to the Analysis of Flows and Spray Characteristics, Atomization and Sprays, vol. 7, pp. 581-601, 1997.

7. V. Yakhot and S. A. Orszag, Renormalization Group Analysis of Turbulence: 1. Basic Theory, J. Sci. Comput., vol. 1, p. 3, 1986.

8. J. Domnick, A. Scheibe, T. Steigleder, G. Weckerle, and Q. Ye, Simulation of the Electrostatic Spray Painting Process with High-Speed Rotary Bell Atomizers, 8th. Int. Conf. on Liquid Atomization and Spray Systems, Pasadena, CA, July 2000. 